\title{
Cytological Studies in Some South Indian Species of Carex
}

\author{
B. H. M. Nijalingappa and D. Leela Bai \\ Department of Botany, Bangalore University, Bangalore 560 056, India
}

Accepted February 16, 1990

Carex, with an estimated 2000-2500 species, is the largest genus of the family Cyperaceae. In India, it is represented by 142 species of which 22 occur in South India (Clarke 1894, Fischer 1931). On the basis of inflorescence morphology, Kükenthal (1909) divided this genus into four subgenera and reorganized 69 sections. However, later authors reorganized his scheme and reduced the subgenera as well as the sections to make them phylogenetically more homogeneous (Kreczetowicz 1935, Ohwi 1936, Koyama 1962, 1985). In addition, Carex has remained a classic example of cytotaxonomic confusion (Heilborn 1939). Therefore, there is a need to apply the methods of biosystematics to understand specific boundaries within the genus and define the sections in terms of a unique pattern of chromosome variation operating therein.

A perusal of literature pertaining to the cytology of Carex revealed that a majority of the species investigated are from temperate zones and many tropical ones have remained either untouched or insufficiently examined (Moore 1973, 1974, 1977, Fedorov 1974). Considering the size of this genus, the cytological work done in India is very inadequate and dealt only with the chromosome counts and no detailed karyotopic study has been made in any of the species studied so far (Table 1). The present investigation deals with the karyotype and meiosis in Carex baccans Nees, C. filicina Nees, C. glaucina Boeck., C. lindleyana Nees, C. longicruris Nees and $C$. longipes D. Don.

Table 1. Previous chromosome counts in species of Carex from India

\begin{tabular}{|c|c|c|c|c|}
\hline Species & Locality & n & $2 n$ & Author (s) \& year (s) \\
\hline \multirow[t]{2}{*}{ Carex baccans Nees } & Kemmangundi & & 46 & Nijalingappa $1975 \mathrm{~b}$ \\
\hline & Tamilnadu & & 84 & Subramanian 1988 \\
\hline C. fedia Nees & Renuka Lake NW India & 47 & - & Bir et al. 1986 \\
\hline \multirow{2}{*}{ C. flicina Nees } & Nainital, Kumaon & 21 & - & Mehra \& Sachdeva 1975 \\
\hline & Darjeeling & 24 & - & Sachdeva 1977 \\
\hline $\begin{array}{l}\text { C. glaucina Boeck. } \\
\text { (C. lindleyana Nees } \\
\text { var. major Fischer) }\end{array}$ & Kemmangundi & - & 46 & Nijalingappa 1975b \\
\hline C. insignis Boott & Darjeeling & 24 & - & Sachdeva 1977 \\
\hline C. longicruris Nees & Udhagamandalam & - & 52 & Nijalingappa et al. 1978 \\
\hline C. longipes Don & Darjeeling & 21 & - & Sachdeva 1977 \\
\hline C. melanantha C. A. Mey & Kashmir & 24 & - & Mehra \& Sachdeva 1975 \\
\hline C. muricata $\mathrm{L}$. & Nainital, Kumaon & 29 & - & $-"-$ \\
\hline C. nubigena Don & Kashmir & 52 & - & $-" 1-$ \\
\hline C. remota $\mathrm{L}$. & Kashmir & 31 & - & $-"-$ \\
\hline C. stenophylla Wahlenb. & Kashmir & 30 & - & $-"-$ \\
\hline
\end{tabular}

\section{Materials and methods}

The materials used in the present investigation were collected in the course of field work in Kemmangundi (Karnataka) during 1967 and Udhagamandalam (Tamilnadu) between 1977 
and 1985. They were maintained in the botanical garden at the Central College campus and subsequently at the Jnanabharathi campus, Bangalore University, Bangalore. The root tips from cultivated materials have been used for the study of somatic chromosomes. Squash preparations were made following Tjio and Levan's (1950) aceto-orcein method. Since the chromosomes lack centromeric constrictions, they were categorized into long (more than 1.5 $\mu \mathrm{m}$ ), medium ( 1.0 to $1.5 \mu \mathrm{m}$ ) and short (less than $1.0 \mu \mathrm{m}$ ) types and abbreviated as $\mathbf{L}, \mathbf{M}$ and $\mathrm{S}$ respectively for purpose of idiogram formulae. Meiosis and first pollen mitosis have been studied using male spikelets fixed in acetic alcohol $(3: 1)$ in the wild. The staining of the squashed anthers has been made in acetocarmine. Dried voucher specimens have been deposited in the Herbarium, Department of Botany, Bangalore University, Bangalore.

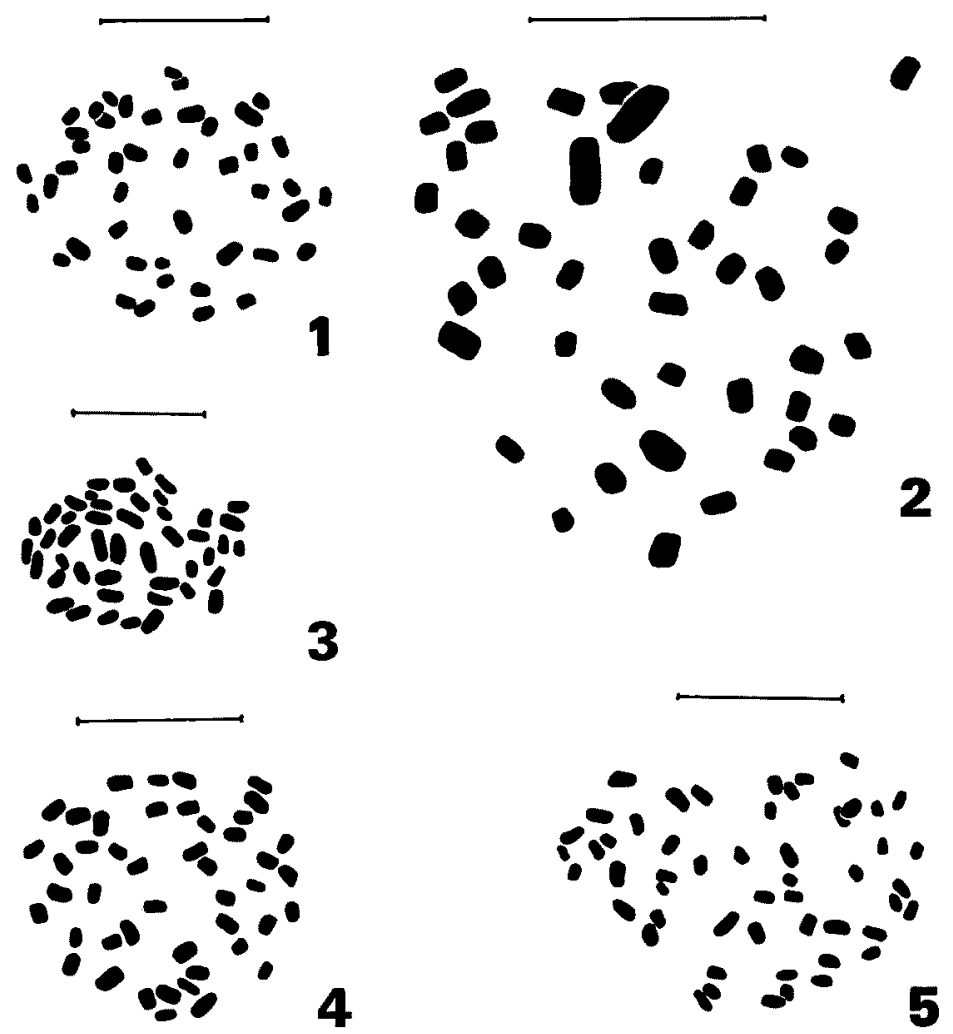

Figs. 1-5. Somatic chromosomes (scale bar $=10 \mu \mathrm{m}) . \quad 1$, Carex filicina $(2 \mathrm{n}=44) . \quad 2$, C. longipes $(2 n=44) . \quad 3$, C. baccans $(2 n=46) . \quad 4$, C. glaucina $(2 n=46) . \quad 5$, C. longicruris $(2 n=52)$.

\section{Observations}

\section{Carex flicina}

The somatic chromosome number of this species is 44 (Fig. 1). The karyotype consists of 14 long chromosomes, 28 medium sized chromosomes and 2 short chromosomes none of which showing any visible constriction and the idiogram formula may be written as $14 \mathrm{~L}+$ $28 \mathrm{M}+2 \mathrm{~S}$. The length of the long chromosomes varies from 1.5 to $2.1 \mu \mathrm{m}$ and four of them appear distinctly larger than the remainder which are of the same length. The medium sized chromosomes, however, exhibit a gradation in size with six pairs each of 1.4 and $1.2 \mu \mathrm{m}$ long and a pair each of 1.1 and $1.0 \mu \mathrm{m}$ long chromosomes. The remaining pair of the complement 
is the smallest one measuring $0.8 \mu \mathrm{m}$ and appears somewhat like a fragment. The total length of the somatic complement is $58.5 \mu \mathrm{m}$.

\section{C. longipes}

This species has 44 chromosomes in the diploid complement (Figs. 2, 7). The karyotype is characterized by $10 \mathrm{~L}+30 \mathrm{M}+4 \mathrm{~S}$. A pair of long chromosomes measuring $2.9 \mu \mathrm{m}$ appears quite distinct from the other chromosomes of the somatic plate by its larger size. Except this pair all others show a gradual size difference. The smallest pair of the complement resembles the corresponding pair of the previous species. The total length of the somatic complement is $59.1 \mu \mathrm{m}$.

\section{C. baccans}

The diploid chromosome number of this species is 46 (Fig. 3). The karyotype includes four pairs of long, 14 pairs of medium sized and five pairs of short chromosomes. The idiogram formula is $8 \mathrm{~L}+28 \mathrm{M}+10 \mathrm{~S}$. The size difference among the chromosomes in the complement is found to be gradual and the length of the chromosomes varies from 0.7 to $1.9 \mu \mathrm{m}$. The total length of the somatic complement is $58.3 \mu \mathrm{m}$.

\section{C. glaucina}

This species has the somatic chromosome number of 46 (Fig. 4). The karyotype includes only long and medium sized chromosomes without notable size differences among them. The idiogram formula is $26 \mathrm{~L}+20 \mathrm{M}$. The length of the chromosomes in the complement ranges from 1.0 to $2.1 \mu \mathrm{m}$ with the total length of the diploid complement being $72.5 \mu \mathrm{m}$.

\section{C. longicruris}

This species shows the chromosome number of $2 n=52$, the highest among the species studied in the present work (Fig. 5). The karyotype is characterized by $20 \mathrm{~L}+30 \mathrm{M}+2 \mathrm{~S}$. The chromosome length varies from 0.9 to $2.1 \mu \mathrm{m}$. The total length of the diploid complement is $73.9 \mu \mathrm{m}$.

\section{C. lindleyana}

Due to non-availability of sufficient living material, the karyotype analysis of this species could not be performed. However, at first pollen mitosis 22 chromosomes have been observed (Fig. 11).

In all the species of Carex studied here, meiosis has been found to be quite normal with regular bivalent formation and equal disjunction of chromosomes during both first and second divisions (Figs. 6, 8, 10, 12-17). After simultaneous cytokinesis in the microspore mother cell, the first pollen mitosis is initiated simultaneously in all the four microspores of a tetrad but is completed only in the functional microspore as the abortive microspores do not show the division beyond the metaphase stage. Furthermore, while the metaphase chromosomes in the functional microspore appear normal, those of the abortive ones look somewhat diminutive (Figs. 9, 11).

\section{Discussion}

Carex is well known for its extensive variation in chromosome numbers ranging almost continuously from $2 n=12$ to $2 n=112$. The occurrence of this unusually wide range of chromosome numbers which are not in multiples of any common basic number led earlier authors to postulate different basic numbers for this genus. While Heilborn (1939) considered 7 as 

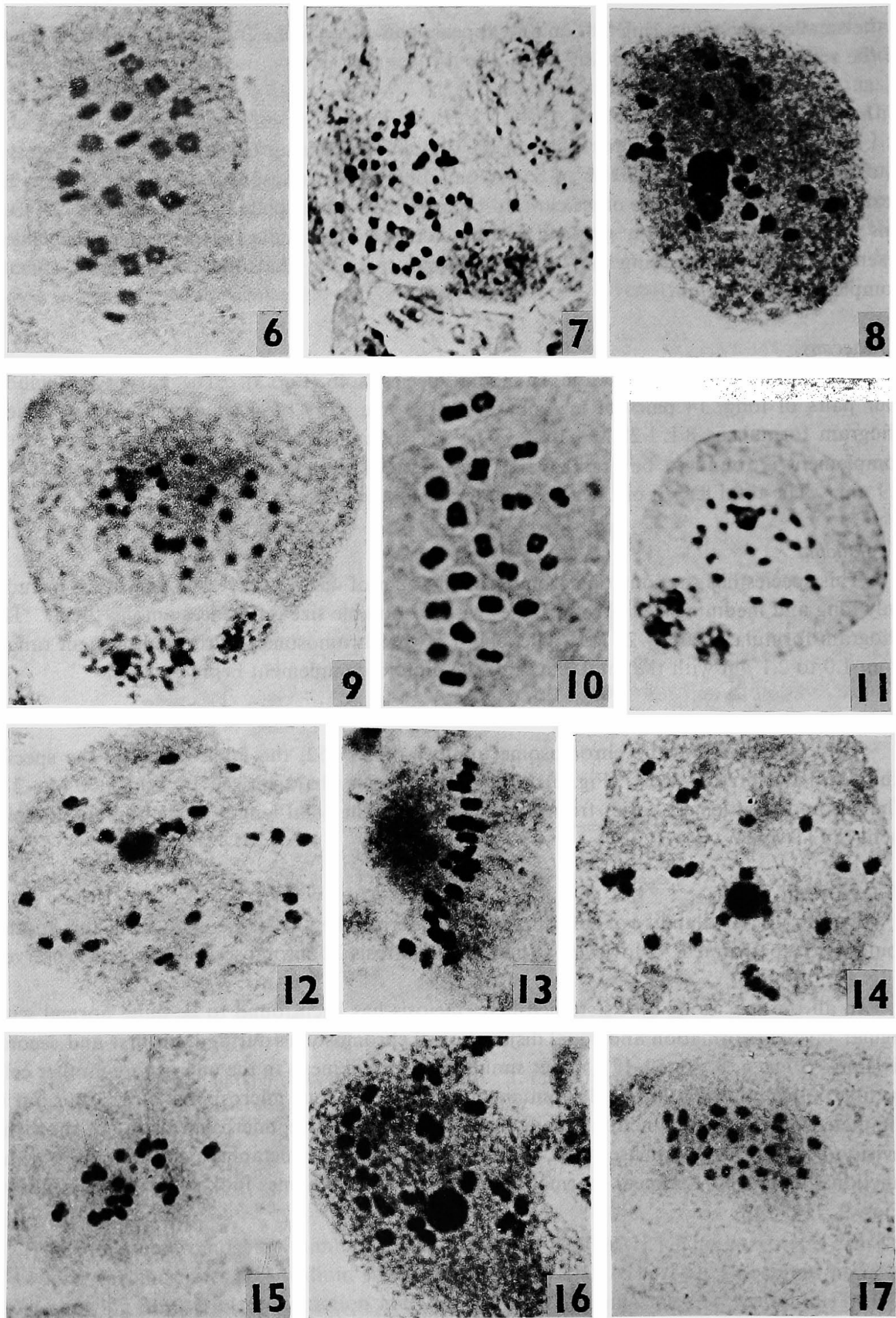

Figs. 6-17. 6, Carex filicina, $\mathrm{n}=22$ at MI. 7, C. longipes, $2 \mathrm{n}=44$, Somatic chromosomes. 8 , C. longipes, $\mathrm{n}=22$ at diakinesis. $9, C$. longipes, $\mathrm{n}=22$ at first pollen mitosis. 10, C. lindleyana, $\mathrm{n}=22$ at MI. 11, C. lindleyana, $\mathrm{n}=22$ at first pollen mitosis. $12, C$. baccans, $\mathrm{n}=23$ at diakinesis. 13, C. baccans, $\mathrm{n}=23$ at MI. 14, C. glaucina, $\mathrm{n}=23$ at diakinesis. 15, C. glaucina, $\mathrm{n}=23$ at MI. $16, C$. longicruris, $\mathrm{n}=26$ at diakinesis. 17, C. longicruris, $\mathrm{n}=26$ at $\mathrm{MI}$. 
the basic number, Wahl (1940) suggested 5, 6, 7 and 8 as the basic numbers and believed that many of the species are derived by secondary balancing at a number just below, or just above, the real euploid numbers from species with a basic number of 7 which is considered as the most typical one for the genus. However, Tanaka (1949) proposed the basic numbers of 3, 4, 5, 6, $8,9,10$ and 12 and treated $x=3,4$ and 5 as the primary basic numbers from which others are derived secondarily through polyploidy. According to Löve et al. (1957), all chromosome numbers within Cyperaceae in general and Carex in particular, have been derived from the original basic number $\mathrm{x}=5$ by fragmentation of chromosomes, which they called partial agmatoploidy. Faulkner (1972), however, opined that the applicability of the base number concept to the genus as a whole is reduced to a virtual absurdity. He criticised the emphasis laid by earlier authors on chance maxima in the frequency distribution of chromosome numbers which formed the basis for the aforesaid diverse propositions on basic numbers and suggested to interpret the same data as a unimodal distribution, with a mean of about $n=30$, the haploid number which, according to him, is more prevalent among the species of Carex.

Barring a few instances of euploidy, the chromosomal variation in the genus Carex is dominated by aneuploidy. The species included in the present investigation also fall in line with the latter. Of the four species of the section Indicae examined here, C. flicina and C. lindleyana show the diploid number of 44 while $C$. baccans and $C$. glaucina have 46 . Whereas the first two species represent a hyperhexaploid condition on the basic number of 7 , the other two appear to be secondarily balanced just before the attainment of hexaploid level on the basic number of 8 . A similar situation is seen in $C$. longipes $(2 n=44)$ and $C$. longicruris $(2 n=52)$ of the section Graciles which, however, are based on $x=7$ and 9 respectively.

Among the six species studied here, Carex lindleyana, C. glaucina and C. longicruris appear to be stable in respect of their chromosome numbers. On the contrary, C. filicina, $C$. baccans and $C$. longipes exhibit lability of having more than one chromosome number in each. The meiotic counts of 21 and 24 recorded in Himalayan plants of $C$. filicina (Mehra and Sachdeva 1975) differ from the present report of $2 n=44$. While plants with $2 n=42$ represent a eudiploid condition of this species, others showing counts deviating from this can only be considered as intraspecific aneuploids. Likewise, the diploid numbers of 44 (Heilborn 1939), 46, (Nijalingappa 1975b) and 84 (Subramanian 1988) have been reported for C. baccans. The present count is in agreement with the earlier report of $2 n=46$, which, however, differs from Heilborn's (1939) count by just two chromosomes as is quite frequently seen in other aneuploids as well. On the contrary, an enigmatic count of $2 n=84$ by Subramanian (1988) showing such a wide disparity and not supported by any illustration appears doubtful. In $C$. longipes, the present report $2 n=44$ is at variance with the earlier meiotic count of 21 recorded for East Himalayan plants (Sachdeva 1977). This is suggestive of a varietal difference between East Himalayan (var. nepalensis Boott) and South Indian (var. dissitiflora C. B. Cl.) plants. Possibly, such a difference in chromosome number observed in $C$. baccans and $C$. filicina may be attributed to different subspecies/varieties that are known to occur in these taxa as well (Koyama 1985). However, a detailed morphological study of the cytologically differentiated materials is required before any generalisation could be made.

The somatic chromosomes in the species of Carex examined here have no centromeric constrictions as reported in all other species of the genus studied so far (Heilborn 1924, Davies 1956, Löve et al. 1957, Bir et al. 1986). The karyotypes usually consist of long, medium and short chromosomes among which the medium ones are more predominant but in C. glaucina where the karyotype has only long and medium sized chromosomes, the former are more in number than the latter. The short chromosomes are relatively few and represented by one (C. filicina and $C$. longicruris), two ( $C$. longipes) or five ( $C$. baccans) pairs but in $C$. glaucina they are absent. Although the chromosomes of three distinct size classes occur within the 
same cell, a correlation of chromosome length to chromosome number in species of different levels of ploidy reveals no obvious sign of agmatoploidy of the Luzula type (Nordenskiold 1951).

In taxa possessing chromosomes without localized centromeres, meiosis is said to be post-reductional (Battaglia and Boyes 1955). From the appearance of chromosome configurations at diakinesis and metaphase $I$ it becomes clear that regular bivalents are formed in the same manner as that observed in other members of Cyperaceae including those of Carex (Strandhede 1965, Faulkner 1972, Nijalingappa 1973, 1975a). However, the chromosomes are too small to allow a detailed analysis to verify the exact course of meiosis. Therefore, the occurrence of post-reductional type of meiosis in Carex is still uncertain.

\section{Summary}

The karyotypes and meiosis in Carex filicina Nees $(2 n=44)$, C. longipes D. Don $(2 n=44)$, C. baccans Nees $(2 n=46), C$. glaucina Boeck. $(2 n=46)$ and $C$. longichuris Nees $(2 n=52)$ and meiosis and first pollen mitosis in $C$. lindleyana Nees $(n=22)$ have been investigated. These species exhibit aneuploid variation in chromosome number which is known to be typical of the genus and form a short aneuploid series with $2 n=44,46$ and 52 . The taxa with $2 n=44$ represent a hyperhexaploid condition on the basic number of $x=7$ and those with $2 n=46$ and 52 appear to be secondarily balanced just below the hexaploid level on $x=8$ and 9 respectively. The diverse mitotic counts reported for C. filicina, C. baccans and $C$. longipes are suggestive of cytological differences among geographically isolated plants indicating intraspecific aneuploidy in these species. The chromosomes are relatively small and vary in length from 0.7 to $2.9 \mu \mathrm{m}$. They have been found to have no localized centromeres. The comparative karyotypic analyses and correlation of chromosome length to chromosome number and meiotic configurations in the species investigated have not lent any support to the occurrence of agmatoploidy as well as the post-reductional meiosis of the Luzula type but the possibility of aneuploid variation by chromosome fission and fusion, as facilitated by the unlocalized centromeres cannot be ruled out.

\section{References}

Battaglia, E. and Boyes, J. W. 1955. Post-reductional meiosis: its mechanism and causes. Caryologia 8: 87-134.

Bir, S. S., Sidhu, M. and Kamra, S. 1986. Karyotypic studies on certain members of Cyperaceae from Punjab, north west India. Cytologia 51: 95-106.

Clarke, C. B. 1894. Cyperaceae. In Hooker, J. D., Flora of British India. Vol. 6. pp. 585-748. L. Reeve \& Co., London.

Davies, E. W. 1956. Cytology, evolution and origin of the aneuploid series in the genus Carex. Hereditas 42: 349-365.

Faulkner, J. S. 1972. Chromosome studies on Carex section Acutae in northwest Europe. Bot. J. Linn. Soc. 65: 271-301.

Fedorov, An. A. 1974. Chromosome Numbers of Flowering Plants. (Reprint) Otto Koeltz Science Publishers, Koenigstein.

Fischer, C. E. C., 1931. Cyperaceae. In Gamble, J. S., Flora of the Presidency of Madras, Pt. 9. pp. 1620-1687. Adlard \& Son, London.

Heilborn, O. 1924. Chromosome numbers and dimensions, species-formation and phylogeny in the genus Carex. Hereditas 5: 129-216.

- 1939. Chromosome studies in Cyperaceae III-IV. Hereditas 25: 224-241.

Koyama, T. 1962. Classification of the family Cyperaceae (2). J. Fac. Sci. Univ. Tokyo, Sec. III, 8: 149-278.

- 1985. Cyperaceae. In Dassanayake, M. D. and Fosberg F. R. (eds). A Revised Handbook to the Flora of Ceylon, Vol. V. pp. 125-405. Oxford and IBH Publishing Co., New Delhi. 
Kreczetowicz., V. I. 1935. Carex. pp. 111-464. In Komarov, V. L. Flora URSS Vol. III.

Kükenthal, G. 1909. Cyperaceae: Caricoideae. In A. Engler, Das Pflanzenreich IV, Vol. 20: 1-824. Engelmann, Leipzig.

Löve, A., Löve, D. and Raymond, M. 1957. Cytotaxonomy of Carex section Capillares. Can. J. Bot. 35: $715-761$.

Mehra, P. N. and Sachdeva, S. K. 1975. Cytology of some W. Himalayan Cyperaceae. Cytologia 40: 497515.

Moore, R. J. 1973. Index to Plant Chromosome Numbers 1967-1971. Costhoek's Uitgeveresmaatschappij B. V. Utrecht.

- 1974. Index to Plant Chromosome Numbers for 1972. Costhoek, Scheltema \& Holkema, Utrecht.

- 1977. Index to Plant Chromosome Numbers for 1973-74. Bohn, Scheltema \& Holkema, Utrecht.

Nijalingappa, B. H. M. 1973. Cytological studies in Eleocharis. Caryologica 26: 513-520.

- 1975a. Cytological studies in Fimbristylis (Cyperaceae). Cytologia 40: 177-183.

- 1975b. IOPB Chromosome Number Reports XLVIII. Taxon 24: 370.

-, Nagaraj, M. and Tejavathi, D. H. 1978. IOPB Chromosome Number Reports LXII. Taxon 27: 531-532.

Nordenskiold, H. 1951. Cyto-taxonomical studies in the genus Luzula I. Somatic chromosomes and chromosome numbers. Hereditas 37: 325-355.

Ohwi, J. 1936. Cyperaceae Japonicae I. A synopsis of the Caricoideae of Japan, including Saghlien, Kuriles, Korea and Formosa. Mem. Coll. Sci. Kyoto Imp. Univ. B. 11: 229-530.

Sachdeva, S. K. 1977. IOPB Chromosome Number Reports LVI. Taxon 26: 269-270.

Strandhede, S. O. 1965. Chromosome studies in Eleocharis subser. Palustres I. Meiosis in some forms with 15 chromosomes. Hereditas 53: 47-62.

Subramanian, D. 1988. Cytotaxonomical studies in south Indian Cyperaceae I. Species from the plains . Cytologia 53: 67-72.

Tanaka, N. 1949. Chromosome studies in the genus Carex, with special reference to aneuploidy and polyploidy. Cytologia 15: 15-29.

Tjio, J. H. and Levan, A. 1950. The use of oxiquinoline in chromosome analysis. Ann. Estac. Exp. de Aula Dei 2: 21-64.

Wahl, H. A. 1940. Chromosome numbers and meiosis in the genus Carex. Am. J, Bot, 27: 458-470. 